\title{
Pheochromocytoma- and paraganglioma-triggered Takotsubo syndrome
}

\author{
Shams Y-Hassan ${ }^{1} \cdot$ Henrik Falhammar $\mathbb{B}^{2,3}$ \\ Received: 1 April 2019 / Accepted: 26 July 2019 / Published online: 9 August 2019 \\ (c) The Author(s) 2019
}

\begin{abstract}
Takotsubo syndrome (TS), also known as neurogenic stunned myocardium or broken heart syndrome, is a recognized acute cardiac syndrome. In about $70 \%$ of cases, the syndrome is preceded by an emotional or a physical stressor. Among the innumerable physical trigger factors that may induce TS are pheochromocytomas and paragangliomas (PPGLs). PPGLassociated cardiovascular complications as "myocarditis", "myocardial infarction", "reversible cardiomyopathies", and "transient repolarization electrocardiographic changes" have been described since more than 70 years. During the last two decades, dozens of cases of PPGL-induced TS have been reported. PPGLs display increased catecholamine levels, sometimes massively elevated, which may trigger TS, most likely through hyperactivation of sympathetic nervous system including the cardiac sympathetic nerve terminal disruption with norepinephrine seethe and spillover. PPGL-induced TS is characterized by a dramatic clinical presentation with hemodynamic compromise and high complication rates. The prevalence of global and apical sparing pattern of TS in PPGL-induced TS is significantly higher than in other TS populations. In this report, the associations of PPGL-induced cardiovascular complications are analyzed, and clinical features, complications, outcome and treatment of PPGL-induced TS are reviewed.
\end{abstract}

Keywords Takotsubo $\cdot$ Pheochromocytoma $\cdot$ Paraganglioma $\cdot$ Catecholamine $\cdot$ Broken heart $\cdot$ Myocardial stunning

\section{Introduction}

Pheochromocytoma is a neuro-endocrine tumor arising from chromaffin cell in the adrenal medulla. Paraganglioma is also a neuro-endocrine tumor arising from extra-adrenal paraganglia [1]. The initial presentation of pheochromocytomas and paragangliomas (PPGLs) may be vague and symptoms and signs may be difficult to interpret [2]. Paroxysmal hypertension and the classic triad of headaches, diaphoresis, and palpitation were the symptoms of catecholamine excess that most commonly lead to the suspicion

$\triangle$ Henrik Falhammar

henrik.falhammar@ki.se

1 Coronary Artery Disease Area, Heart and Vascular Theme, Karolinska Institutet and Karolinska University Hospital, Stockholm, Sweden

2 Department of Endocrinology, Metabolism and Diabetes, Karolinska University Hospital, Stockholm, Sweden

3 Departement of Molecular Medicine and Surgery, Karolinska Institutet, Stockholm, Sweden of PPGLs previously but are not so common presentation nowadays [1-4]. PPGLs are generally rare but may be more common in certain groups such as in patients with adrenal incidentalomas where $0.6-4.2 \%$ can be affected [5-7]. The majority of PPGLs are currently diagnosed during the workup of an incidentaloma, then PPGL-related symptoms and lastly due to screening for a known hereditary syndrome (such as multiple endocrine neoplasia type 2, von Hippel Lindau syndrome, neurofibromatosis type 1, and mutations in succinate dehydrogenase $\mathrm{B}, \mathrm{C}$, and D) $[2-4,8]$. Occasional cases are found with Cushing's syndrome due to ectopic ACTH-production from the PPGL [9, 10], and all adrenal tumors should be investigated with a $1 \mathrm{mg}$ overnight dexamethasone suppression test to exclude cortisol excess $[11,12]$. In about three quarters of the patients with PPGLs, there will be overproduction of both epinephrine and norepinephrine. In the remainder, there is only norepinephrine secretion, especially in paragangliomas where the clear majority only has norepinephrine secretion $[1,8]$.

Takotsubo syndrome (TS), also known as neurogenic stunned myocardium or broken heart syndrome, is a recently recognized acute cardiac disease entity [13, 14]. The term takotsubo $($ tako $=$ octopus, tsubo $=\mathrm{a}$ pot $)$ was 
introduced in the beginning of 1990s by Sato and Dote to describe the left ventricular silhouette during systole in patients presenting with clinical features typical for that of myocardial infarction but demonstrated no obstructive coronary artery disease $[15,16]$. The syndrome has a clinical presentation, electrocardiographic changes, and "myocardial infarction biomarker" elevation indistinguishable from that of an acute coronary syndrome (ACS) [14]. The main defining feature of TS is the regional and circumferential pattern of left ventricular wall motion abnormality (LVWMA) resulting in a conspicuous ballooning of the left ventricle during systole [17]. The left ventricular dysfunction extends beyond the coronary artery supply regions and is reversible with almost complete resolution of ventricular dysfunction in hours to weeks $[13,17]$. The LVWMA may be localized to the apical, mid-apical, mid-ventricular, midbasal or basal segments of the left ventricle (Fig. 1) [13]. A focal or global left ventricular contractile abnormality has also been reported $[14,18]$. The right ventricle may be involved in about one third of the TS patients [19]. The syndrome is preceded by a trigger factor in about $70 \%$ of patients $[14,20]$. Emotional triggers as death of a close relative or acute grief may trigger the syndrome and hence the term broken heart syndrome [21]. Innumerable physical triggers, extending from serious diseases as intracranial hemorrhages, sepsis to the most physiological processes as sexual intercourse, and pregnancy, may also trigger the syndrome [22]. One of the important and well-documented trigger factors is the external administration of epinephrine [23] or norepinephrine [24], and PPGLs [25, 26]. During the last two decades, dozens of cases of PPGL-triggered TS have been described $[25,26]$. The aim of this review is to provide an up to date summary of available knowledge of PPGL-triggered TS.

\section{Pathogenesis}

Severe signs and symptoms of PPGLs with massively increased catecholamine levels may act as a strong physical stressor triggering TS [14]. The most probable pathologic mechanism of PPGL-induced TS is illustrated in Fig. 1. In general, the pathogenesis of TS is still elusive and is discussed in detail elsewhere [13, 17]. In brief, several pathophysiological mechanisms for the development of TS have been proposed. The main proposed mechanisms are myocardial ischemia, left ventricular outlet tract obstruction (LVOTO), blood-borne catecholamine myocardial toxicity, epinephrine-induced switch in signal-trafficking, and autonomic nervous system dysfunction with sympathetic nervous system hyper-activation, including local cardiac sympathetic disruption and norepinephrine seethe and spillover. Evidences, challenging the first four proposed mechanisms and supporting the fifth one, are substantial and

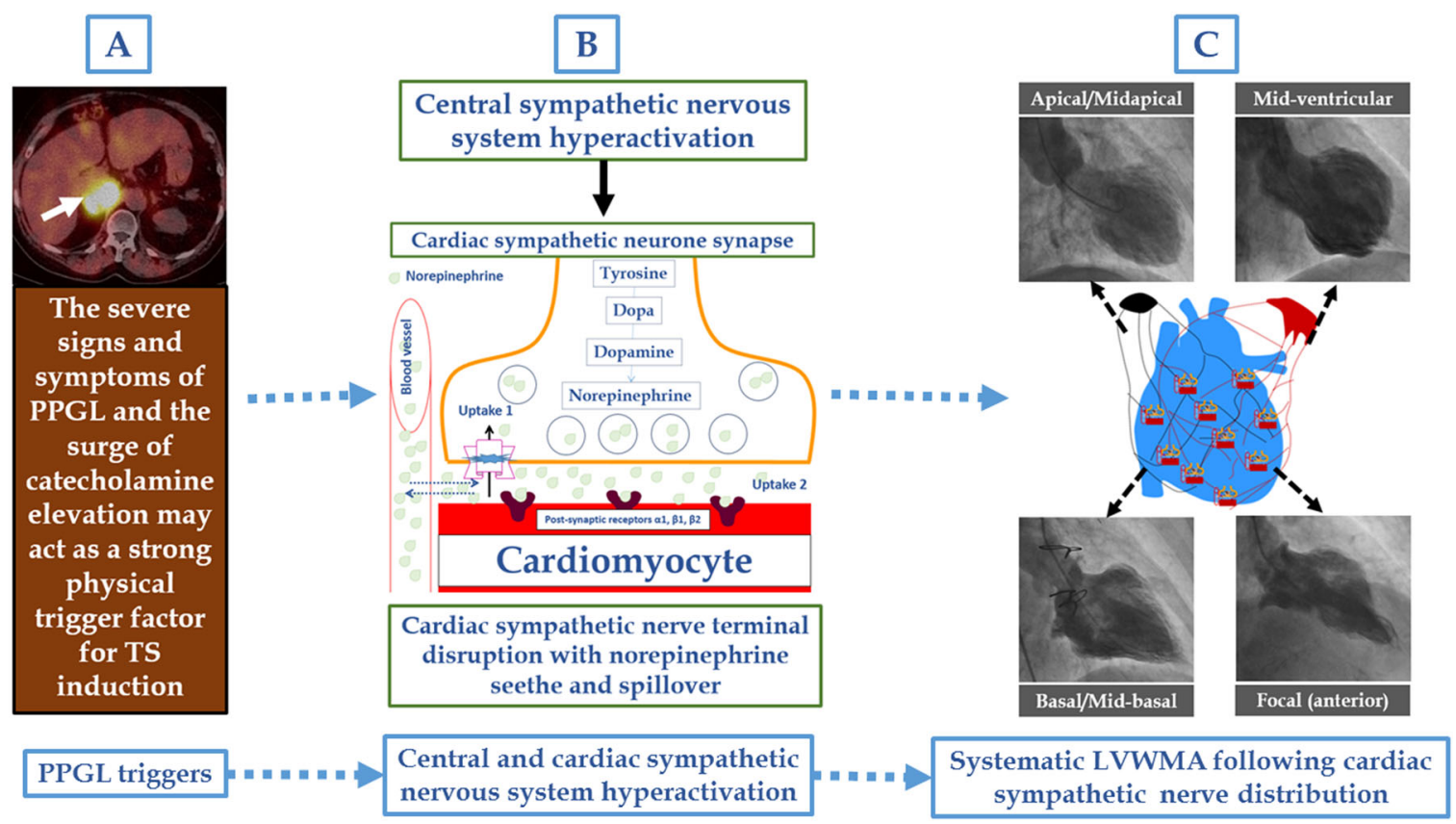

Fig. 1 Pathogenesis of pheochromocytoma and paraganglioma (PPGL)-induced takotsubo syndrome (TS). PPGL is a strong physical trigger factor a and may trigger the autonomic (sympathetic) nervous system and result in sympathetic cardiac nerve terminal disruption and norepinephrine spillover $\mathbf{b}$. This results in myocardial stunning, which most probably follow the cardiac sympathetic nerve distribution causing circumferential left ventricular wall motion abnormality (LVWMA) and may be localized to apical or mid-apical, midventricular, basal or rarely focal regions as illustrated in $\mathbf{c}$ 
detailed elsewhere [13, 17]. The apical sparing patterns in mid-ventricular and basal types of TS strongly challenges the coronary myocardial ischemia, LVOTO, and the epinephrine-induced switch in signal trafficking hypotheses [17]. Long-lasting (hours or even days) ST-segment elevation in patients with TS and modest troponin elevation, the histopathological findings of contraction band necrosis, which is distinct from the myocardial infarction necrosis, also argue against coronary myocardial ischemia [13]. LVOTO is a complication rather than a cause of TS [17]. Apart from PPGLs, plasma epinephrine levels in TS is usually normal or moderately elevated, and the increased prevalence of apical sparing TS in epinephrine- or PPGLinduced TS also challenges a direct causal link between epinephrine and TS [27]. Worth mentioning is that myocardial ischemia, plasma catecholamines, and epinephrine administration may act as trigger factors, as any other physical stress factors, for TS induction [13, 28]. In addition, TS may cause myocardial infarction through left ventricular thrombus formation and coronary thromboembolism [29].

The evidences for the involvement of autonomic (sympathetic) nervous system including sympathetic cardiac nerve terminal disruption with norepinephrine seethe and spillover are substantial [17]. The deep anguish that arises from bereavement and induces TS in an individual argues for an excessive sympathetic stimulation of the myocardium likely mediated via the brain [30]. The TS-induction after acute intracranial diseases, such as intracranial and subarachnoid hemorrhage, thrombotic stroke, and epilepsy strongly suggests the involvement of the sympathetic nervous system in the pathophysiology of TS [13]. Signs of cardiac sympathetic denervation assessed by ${ }^{123} \mathrm{I}$-metaiodobenzylguanidine $\left({ }^{123} \mathrm{I}\right.$ MIBG) scintigraphy have been demonstrated at regions with LVWMA in patients with TS. Elevated norepinephrine levels in the coronary sinus in patients with TS suggest increased local myocardial catecholamine release from the sympathetic cardiac nerve terminals [13]. Other evidences for the involvement of autonomic (sympathetic) nervous system including sympathetic cardiac nerve terminal disruption with norepinephrine seethe and spillover are delivered in detail in two reviews $[13,17]$.

\section{PPGL and cardiovascular complications including TS}

Historically, during the last seven decades, pheochromocytoma has been described in association with "myocarditis"[31], "acute myocardial infarction" [32], "reversible cardiomyopathy "[33], "left ventricular dysfunction" [34], repolarization electrocardiographic changes, and different other cardiac complications as arrhythmias, cardiogenic shock, and pulmonary edema [34]. During the last two decades, dozens of cases of PPGL-triggered TS have been reported $[25,26]$, the majority being due to pheochromocytomas, however, paragangliomas were the culprit in $6 \%$.

In addition to the characteristic circumferential LVWMA, TS has a clinical presentation identical to acute myocardial infarction, characteristic repolarization ECG changes, cardiac magnetic resonance (CMR) imaging findings consistent with focal myocarditis in one third of patients, and diverse cardiac complications as arrhythmias, pulmonary edema and cardiogenic shock. Having these TS features in mind, critical analysis of some of the reported PPGL-associated myocarditis, myocardial infarction, reversible cardiomyopathy and when enough investigations were performed reveals that those cases have features consistent with TS.

\section{PPGL and myocarditis}

During more than 50 years and still cases of PPGL-induced acute "myocarditis", commonly focal myocarditis, confirmed by either endomyocardial biopsy, autopsy [31], or by CMR imaging [35] have been reported. Critical analysis of at least some of these cases having been investigated with ECG and echocardiography shows that these patients also have features consistent with TS. As late as 2018, a 25-yearold man was reported with pheochromocytoma and CMR imaging findings consistent with "acute myocarditis" at the basal segments of the left ventricle [35]. However, the ECG findings of widespread ST-depression and the hypokinesis of the basal segments with both echocardiography and CMR imaging argue strongly for basal TS pattern (inverted TS) with late gadolinium enhancement at the basal segments. CMR imaging may show patchy late gadolinium enhancement in one third of patients with TS [36].

\section{PPGL and myocardial infarction}

Cases of PPGL-induced chest pain and ECG findings of "myocardial infarction" have been reported [32, 37, 38]. Detailed analysis of some of those cases reveals findings consistent with TS. In 1983, McGonigle et al. [32] reported on a 38-year-old house wife with "recurrent myocardial infarction". The patient was showed to have a pheochromocytoma. During one admission, the patient had reversible marked ST-elevation with tombstone appearance. The coronary arteries were normal. Left ventriculography revealed discrete left ventricular apical "aneurysm" with clot in the aneurysmal sac. With the current knowledge, this case can justifiably be deemed as recurrent TS triggered by a pheochromocytoma. Worth mentioning, tombstone ST-elevation has been described in TS [39]. In 1990, Nirgiotis et al. [38] described the association of "acute myocardial infarction" 
and pheochromocytoma in a 14-years-old girl. Coronary artery disease is very unlikely in this teenage girl and PPGL-triggered TS is in hindsight the most likely diagnosis. In 1993, Jessurun et al. [40] described the case of a 30-yearold pregnant woman that during the 33rd week of gestation suffering "acute anterior myocardial infarction with non-Q reinfarction" in association with pheochromocytoma. Echocardiography showed left ventricular dilatation, septal akinesis, and depressed left ventricular ejection fraction of $35 \%$. She had normal coronary arteries. The description of this case is consistent with PPGL-triggered TS.

\section{PPGL and reversible cardiomyopathy}

Cases suggested to have "reversible cardiomyopathy" induced by PPGL were reported 50 years ago [33]. The "suggested cardiomyopathy" in those patients improved by therapy with alpha receptor blockers prior to adrenalectomy [33]. Cases of reversible symmetrical deep T-wave inversion after treatment with phenoxybenzamine, a non-selective, irreversible alpha receptor blocker, in patients with "cardiac arrhythmia and cardiomyopathy" associated with pheochromocytoma have been described [41]. Cases of "reversible pheochromocytoma-induced cardiomyopathy", which may have been global TS, have also been reported. In 1988, case records of the Massachusetts General Hospital [42] presented the case of a 20-year-old lady who was admitted because of the question of "dilated cardiomyopathy and stroke". Investigation showed pheochromocytoma presented with "cardiomyopathy" complicated by embolic stroke of cardiac origin. Critical analysis of the echocardiography and left ventriculography reveals a typical case of reversible mid-basal (inverted) TS triggered by pheochromocytoma. In 2015, Batisse-Lignier et al. [43] reported on acute and chronic pheochromocytoma-induced cardiomyopathies. The authors systematically reviewed 145 published cases and classified them to "takotsubo cardiomyopathy" (49 patients) and "catecholamine cardiomyopathy" (96 patients). The cases were classified to TS if they were meeting the John Hopkins classifications criteria for TS [44]. Both groups had similar clinical presentation. Acute pulmonary edema was more frequent in "catecholamine cardiomyopathy". Higher and better recovery of left ventricular ejection fraction was observed in patients with TS. The authors deemed that the two types of cardiomyopathies appeared to have different pathophysiological pathways. However, the two types of "cardiomyopathies" may be explained by the same pathophysiological mechanism and the difference is that the so called "catecholamine cardiomyopathy" is a more severe form of TS; the left ventricular wall motion abnormality is global and probably these patients had recurrent TS and a longer period of undiagnosed pheochromocytomas.

\section{PPGL and left ventricular dysfunction}

Several other cases of reversible left ventricular dysfunction induced by PPGLs without mentioning TS have been described. In 1987, Shaw et al. [34] described the case of a 41-year-old man as a transient shock and myocardial impairment induced by a pheochromocytoma crisis. The patient had normal coronary arteries. The authors stated, "across sectional echocardiogram showed akinesia of all areas of the left ventricle except the basal segments". Consequently, the findings in this case are typical for midapical TS pattern induced by PPGL. In 1989, Iga et al. [45] described a case entitled "reversible left ventricular wall motion impairment caused by pheochromocytoma". A figure in the article shows an echocardiography finding typical for mid-apical ballooning consistent with mid-apical TS triggered by PPGL. In 2010, Roubille et al. [46] described the case of a 35-year-old woman with typical recurrent midbasal (inverted) TS induced by pheochromocytoma but the cardiac condition was described as apical sparing mid and basal left ventricular dysfunction and the term TS was not mentioned.

\section{PPGL-induced hypercontracted sarcomere and contraction band necrosis}

Contraction band necrosis (CBN), also referred to as coagulative myocytolysis and myofibrillar degeneration, is characterized histologically by dense irregular eosinophilic clumping of the sarcoplasm with intervening cleared areas [47]. One of the reported causes of CBN is both external administration of catecholamines and endogenous catecholamine elevations [47]. A consistent histopathological finding in patients with TS is the demonstration of CBN [48]. PPGL-induced hypercontracted sarcomere and CBN as that seen in TS has also been reported [49].

\section{Clinical features, complications, and outcomes of PPGL-induced TS}

The reported mean age of the patient population in PPGLinduced TS was about 46 years, which was almost 20 years younger than all-triggered TS population [25, 50]. The prevalence of PPGL-induced TS in men was increased to $30 \%$ compared to only $10 \%$ in other all-TS populations [50]; however, women were still predominating in PPGLinduced TS. The most common presenting symptoms were chest and abdominal pain, dyspnea, and headache. Signs and symptoms suggestive of PPGL, such as pallor, profuse sweating, palpitations, labile blood pressure, and headache were present in almost $75 \%$ of patients [25]. The most common ECG changes during presentation were ST- 
elevation myocardial infarction (STEMI) like changes (38\%), ST-depression (25\%), T-wave inversion (14\%), nonspecific changes (9\%), sinus tachycardia (11\%), and tall peaked T-wave (1\%) [25]. A characteristic feature of PPGLinduced TS was the increased prevalence of global TS pattern $(20 \%)$ and basal pattern $(30 \%)$ compared to $0 \%$ and $2.2 \%$ respectively in all-TS population $[25,50]$. The apical sparing pattern of TS occurred in 35\% (basal 30\% and midventricular 5\%) of patients with PPGL-induced TS $[25,51]$. The "classical" apical (apical and mid-apical) TS pattern was significantly lower (44\% compared to $83 \%$ ) in PPGL-induced TS than all-TS population. Interestingly, the STEMI-like ECG changes and T-wave inversions were found almost exclusively in the apical or midventricular patterns of TS and the ST-depression or peaked T-wave occur in the basal patterns of TS [25]. The occurrence of the apical TS in less than half of the cases, apical sparing (basal and mid-ventricular) pattern in $35 \%$ of cases and the global pattern in $20 \%$ of cases strongly challenges the epinephrineinduced switch in the intracellular signal trafficking hypothesis causing TS proposed by Lyon et al. [52]. Figure 2 and 3 illustrate typical cases of mid-apical and mid-basal (inverted) TS patterns; both cases were triggered by pheochromocytomas.
It should be noted that the description of LVWMA is not always accurate in PPGL-induced TS. Patients with PPGLinduced TS may deteriorate rapidly, and the TS localization may transform from regional to global [53]. Such change has been well-demonstrated in the case reported by Flam et al. [53] where the patient had mid-basal TS pattern during the first admission day and this very rapidly progressed to severe biventricular failure during the following day. A similar case of paraganglioma-induced TS with development of biventricular heart failure was recently reported by Ferreira et al. [54]. Cases with PPGL-induced TS with such startling course complicated by respiratory failure, metabolic acidosis and cardiogenic shock have been reported $[55,56]$. In a study of 140 patients with PPGLs, Giavarini et al. [57] found that $15(11 \%)$ patients suffered "acute catecholamine cardiomyopathy". Six out of 15 patients displayed classical mid-apical or inverted (mid-basal) TS. The remainder had severe extensive or global hypokinesia and a clinical manifestation of pulmonary edema. These findings may indicate that patients with PPGL-triggered global biventricular failure may in fact have global TS.

PPGL-induced TS is characterized by high complication rates. Two thirds of PPGL-induced TS developed some kinds of complications and almost one third of patients had
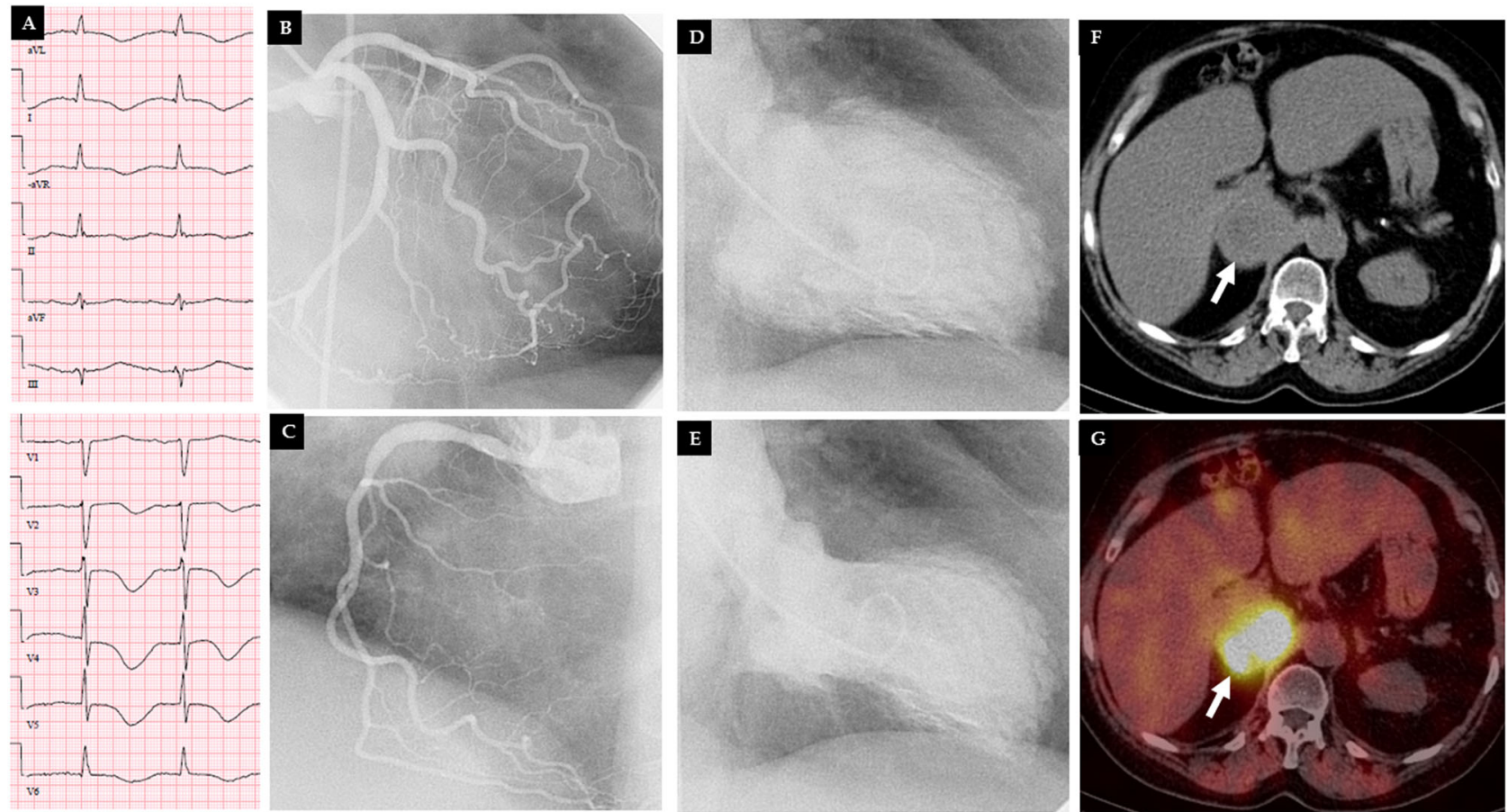

Fig. 2 A typical case of mid-apical takotsubo syndrome (TS) pattern triggered by pheochromocytoma. The 12-lead electrocardiogram a shows T-wave inversions in the anterolateral leads with marked QTc prolongation $595 \mathrm{~ms}$. Coronary angiography shows b normal left coronary artery (LCA), and c right coronary artery (RCA). Left ventriculography during diastole $\mathbf{d}$ and systole e shows mid-apical left ventricular ballooning consistent with TS. Abdominal computed tomography $\mathbf{g}$ reveals right adrenal tumor (white arrow); abdominal iodine-123 meta-iodobenzylguanidine ( $\left.{ }^{123} \mathrm{I}-\mathrm{MIBG}\right)$ single-photon emission computed tomography displayed abnormal uptake of radiotracer within right adrenal pheochromocytoma (h, white arrow) 

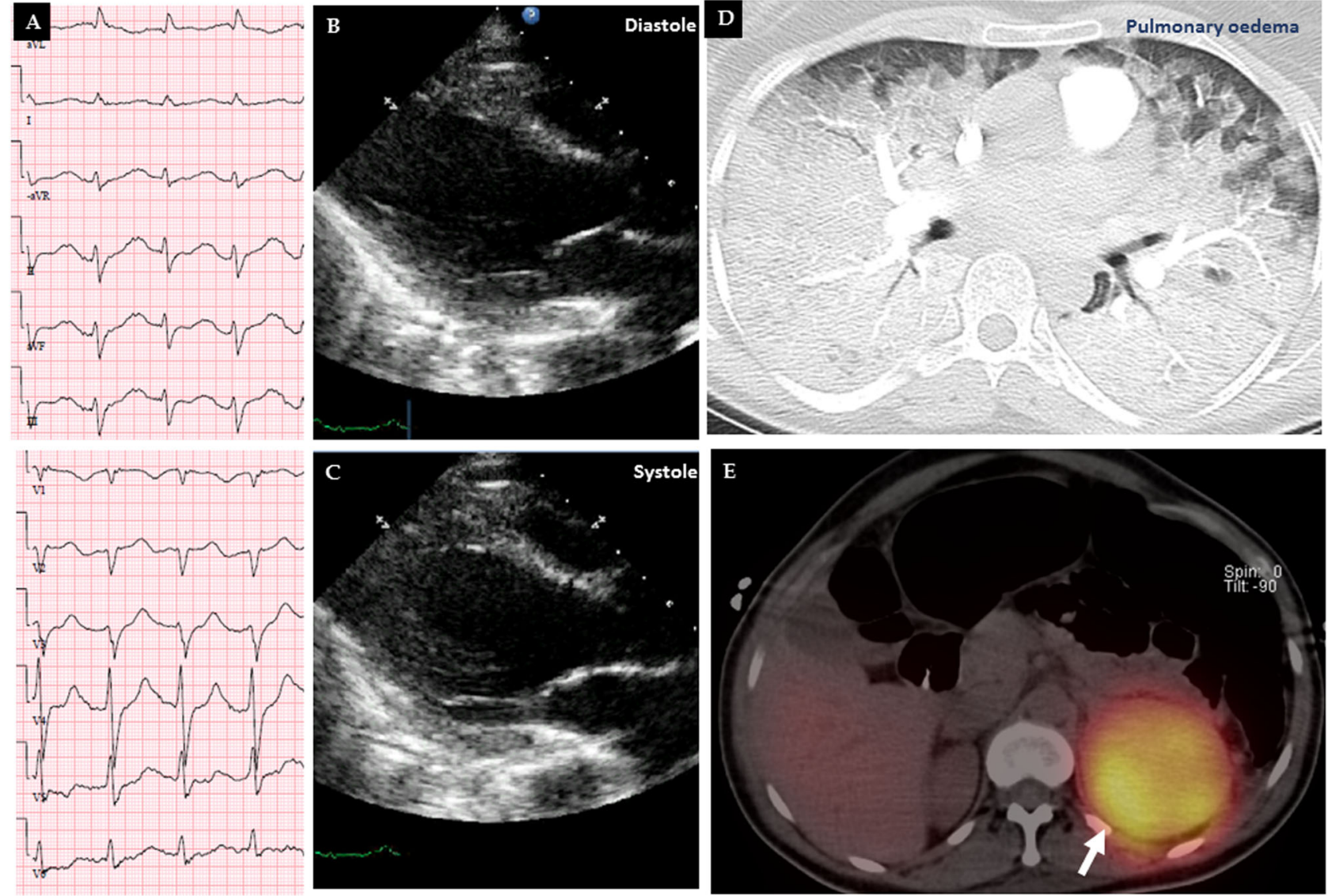

Fig. 3 A case of mid-basal (inverted) takotsubo syndrome (TS) pattern triggered by pheochromocytoma. The 12-lead ECG reveals sinus tachycardia, ST-depressions in leads II, III, aVF, and V3-V6 a. Echocardiography during diastole $\mathbf{b}$ and systole $\mathbf{c}$ shows akinesia in the middle and basal segments of the left ventricle with normal

multiple complications in a review study of 80 patients [25]. The complication rates in PPGL-induced TS are significantly higher than that in all-TS population reported by Templin et al. [50], Sharkey et al. [22], and Gianni et al. [58]. The combined endpoint of serious in-hospital complications, reported by Templin et al. [50] was 21.8\%, which was significantly lower than the complication rates (68\%) in PPGL-induced TS. The most important risk factors for the development of complications in PPGL-induced TS were; first, TS-localization pattern; the global TS localization had significantly higher hemodynamic complications than the apical TS-localization pattern. On the other hand, the thrombo-embolic complications occur mainly in the apical TS pattern [25]. Second, patients with PPGLinduced TS younger than 50 years suffered significantly higher complication rates compared to patients older than 50 years. Two out of 80 patients $(2.5 \%)$ died [59, 60]; there was no difference in the in-hospital mortality between PPGL-induced TS and all-TS. Recurrence occurred in approximately a fifth of patients with PPGL-induced TS; the disease recurred twice in two cases and five times in one contractions of the apical segments. Thoracic computed tomography scan with intravenous contrast showed signs suggestive of pulmonary edema $\mathbf{d}$ and the iodine-123 meta-iodobenzylguanidine ( ${ }^{123}$ I-MIBG) scan reveals a luminous left adrenal tumor mass due to high tracer uptake e

case $[25,61]$. In one case, the patient developed multiple complications with multi-organ failure and resistant fever and died within hours during the recurrence, which occurred six months after the first attack [59]. The recurrence rate was significantly higher than that in all-TS reported by Templin et al. [50] of 3\% and that reported by Sharkey et al. [22] of 5\%. The high recurrence rate of TS in the PPGLinduced TS population is most probably attributed to the delay in the diagnosis of PPGLs where episodes of catecholamine excess have acted as a trigger factor [61]. The cardiac findings of PPGL-induced TS have been summarized in Table 1.

\section{Diagnosis of PPGL-induced TS}

Cardiovascular symptoms as chest pain or dyspnea and sometimes abdominal pain associated with signs and symptoms of catecholamine excess, such as pallor, profuse sweating, palpitations, labile blood pressure, and headache should raise the suspicion of PPGL-induced TS [25]. New 
Table 1 Summary of cardiac findings in pheochromocytoma- and paraganglioma-triggered takotsubo syndrome

Presenting symptom: chest pain may occur in $42 \%$ of patients; a substantial number of patients may present with hemodynamic compromise and signs and symptoms suggestive of PPGL

Tachycardia with reported mean heart rate during presentation $116 \pm$ $30 / \mathrm{min}$

ECG changes: STEMI-like changes occur in more than one third of patients, ST depression in one fourth of patients, and T-wave inversion in $14 \%$

Mild-moderate elevation of "myocardial infarction biomarkers" in $95 \%$ of patients

TS localization pattern is apical in $44 \%$, midventricular in 5\%, basal or inverted in $30 \%$, global in 20 , and focal in $1 \%$. Left ventricular ejection fraction (LVEF) is markedly decreased (mean LVEF $27.7 \%$ \pm 11.6 ) in most of the patients

High in-hospital complication rate, which may occur in two thirds of patients

Heart failure or pulmonary edema may occur in half of patients. Biventricular heart failure has also been reported

Cardiogenic shock occurs in one third of patients

Multiple complications (heart failure, pulmonary edema, cardiogenic shock, circulatory and respiratory failure) may occur in $31 \%$ of cases.

Cardiac thrombo-embolic complications may occur in $8 \%$ where most occur in apical pattern of TS

Arrhythmias may occur in $6.4 \%$, cardiac arrest in 5\% and electromechanical dissociation in $3.8 \%$

Left ventricular outlet tract obstruction has also been reported

Relatively low in-hospital death rate $(2.5 \%)$

Recurrence rate occurs in $18 \%$ of patients and is usually due to delay of the PPGL diagnosis

PPGL-induced cardiomyopathy, myocarditis and myocardial infarction have been reported

$E C G$ electrocardiogram, $P P G L$ pheochromocytoma and paraganglioma, TS takotsubo syndrome, STEMI ST elevation myocardial infarction. For references, please see the main text

ECG changes and elevation of "myocardial infarction" biomarkers should lead to investigation with cardiac image study as echocardiography, which may display the typical LVWMA seen in TS [14]. Echocardiography is a feasible cardiac image study and can be repeated to follow the evolution of LVWMA, to detect TS-complications (as LVOTO, left ventricular thrombus, and development of biventricular heart failure), and to confirm the recovery of LVWMA [17]. CMR imaging is an excellent cardiac image study, which in addition to the above-mentioned findings seen in echocardiography [19], can also differentiate between myocardial infarction, acute myocarditis, and TS $[14,19,20]$. Because PPGL is an important, albeit rare, physical trigger factor for TS, checkup of catecholamine levels, preferably plasma free metanephrines or urinary fractionated metanephrines are essential $[2,8,25,62]$.

\section{Treatment of PPGL-induced TS}

Treatment of TS is discussed elsewhere in details [17]. In brief, proper diagnosis and treatment of predisposing and triggering factors or diseases is crucial in the management of TS. Because of the transient nature of the disease, supportive therapy is indicated during the acute and subacute stages of the disease. In treatment of cardiogenic shock as a complication of PPGL-induced TS, it is fundamental to differentiate between LVOTO or primary pump failure as both conditions may cause severe hypotension and may be deemed as cardiogenic shock $[17,20]$. The treatment of the two complications is quite different. Beta-blockers are crucial in the treatment of LVOTO. However, it should be noted that the use of beta-blockers is contraindicated in PPGLs in the absence of alpha-blockage due to unopposed stimulation of alpha-receptors and the potential risk of hypertensive crisis $[62,63]$. Intravenous fluid administration may be considered in LVOTO caused by PPGLinduced TS [17, 20]. Extracorporeal life support as extracorporeal membrane oxygenation or left ventricular assist treatment as a bridge to recovery of left ventricular function is the most important measure in primary pump failure $[17,20]$. Inotropic catecholamine administration is generally contraindicated in both LVOTO and primary pump failure [17], and in PPGL-induced LVOTO or primary pump failure it is likely even worse. Heart failure is treated with angiotensin converting enzyme inhibitor and betablockers with the caution mentioned above of unopposed stimulation of alpha-receptors. Patients with documented left ventricular thrombus, thrombo-embolic events and those with extensive mid-apical ballooning are treated with anticoagulation for 2-3 months or until the left ventricular dysfunction is resolved [29].

The definite treatment of PPGLs are the surgical removal of the tumor after confirming and localizing the tumor. Up titration of alpha-adrenergic antagonists are crucial in the perioperative period $[8,62]$. Intravenous phentolamine, a reversible nonselective alpha-antagonist, and oral phenoxybenzamine, an irreversible nonselective alpha-antagonist, have traditionally been used for vasoconstrictive blockade and reduce the complications of malignant hypertension. Phenoxybenzamine use generally gives rise to orthostatic hypotension, reflex tachycardia, nasal congestion, dizziness and syncope. However, specific alpha ${ }_{1}$-antagonists, such as doxazosin, prazosin and terazosin, are also effective and often preferred for its shorter half-life, less adverse effects and less complicated management once the blood flow to the tumor has been ceased during surgery [62, 64]. Added benefits with specific alpha ${ }_{1}$-antagonists compared with phenoxybenzamine consist of avoidance of reflex tachycardia by the unopposed alpha 2 -receptor, i.e., preoperative beta-blockers is generally not necessary $[64,65]$. However, 
beta-blockers are still necessary in the treatment of LVOTO (vide supra) in the acute stage. At least 1-2 weeks of alphablockage are needed before surgery, often a lot longer and with doses much higher than recommended in other conditions such as hypertension [8, 62, 64]. The timing of surgical removal in patients with PPGL-induced TS is usually later than in patients without PPGL-induced TS since the cardiac complications have to be controlled. Numerous echocardiogram may be needed before surgery to ascertain stable cardiac function. Realistically it usually takes at least 6 weeks, often months, before the patient with PPGL-induced TS can have surgery.

\section{Cardiac prognosis of PPGL-induced takotsubo syndrome}

PPGL-induced TS is a serious disease with a dramatic clinical presentation and high complication rate $(68 \%)$. However, the reported in-hospital mortality rate is relatively low $(2.5 \%)$ [25]. The remainder recovers if treated appropriately [25]. The crucial points in improving the prognosis are as follows: first, to diagnose both conditions as early as possible. If PPGL continues to be undetected, there is a great risk of TS recurrence with additional risks of complications and permanent myocardial damage. The reported TS recurrence is high (18\%) [25]. Second, two thirds of patients with PPGL-induced TS develop complications, more than one third develop cardiogenic shock, and in others progress to global biventricular heart failure $[25,53,54]$. The most important point is to avoid inotropic medications, which have a deleterious effect. Such patients should be treated with extracorporeal life support as extracorporeal membrane oxygenation. Di Vece et al. [66] have recently reported significantly lower in-hospital cardiac mortality in patients with TS complicated by cardiogenic shock if they were treated with cardiac mechanical support compared to those treated without.

\section{Conclusion}

PPGL-triggered TS is characterized by a dramatic clinical presentation with high complication rates and may be fatal if not recognized and promptly managed. The prevalence of global and apical sparing pattern of TS in PPGL-induced TS is significantly higher than in other TS populations. PPGLinduced TS has often been misdiagnosed as "myocarditis", "acute myocardial infarction", and "reversible cardiomyopathy". Patients with PPGL-induced TS may deteriorate rapidly and develop global and sometimes biventricular heart failure or cardiogenic shock. It is therefore essential for clinicians to be aware of the clinical presentation and manifestations of PPGL-induced TS since early identification can be life-saving.

Acknowledgements Open access funding provided by Karolinska Institute.

Funding This study was funded by Magnus Bergvall Foundation (Grant Number 2017-02138 and 2018-02566).

\section{Compliance with ethical standards}

Conflict of interest The authors declare that they have no conflict of interest.

Publisher's note: Springer Nature remains neutral with regard to jurisdictional claims in published maps and institutional affiliations.

Open Access This article is distributed under the terms of the Creative Commons Attribution 4.0 International License (http://crea tivecommons.org/licenses/by/4.0/), which permits unrestricted use, distribution, and reproduction in any medium, provided you give appropriate credit to the original author(s) and the source, provide a link to the Creative Commons license, and indicate if changes were made.

\section{References}

1. J.W. Lenders, G. Eisenhofer, M. Mannelli, K. Pacak, Phaeochromocytoma. Lancet 366(9486), 665-675 (2005). https://doi. org/10.1016/S0140-6736(05)67139-5

2. H. Falhammar, M. Kjellman, J. Calissendorff, Initial clinical presentation and spectrum of pheochromocytoma: a study of 94 cases from a single center. Endocr. Connect 7(1), 186-192 (2018). https://doi.org/10.1530/EC-17-0321

3. L. Amar, A. Servais, A.P. Gimenez-Roqueplo, F. Zinzindohoue, G. Chatellier, P.F. Plouin, Year of diagnosis, features at presentation, and risk of recurrence in patients with pheochromocytoma or secreting paraganglioma. J. Clin. Endocrinol. Metab. 90 (4), 2110-2116 (2005). https://doi.org/10.1210/jc.2004-1398

4. L.M. Gruber, R.P. Hartman, G.B. Thompson, T.J. McKenzie, M. L. Lyden, B.M. Dy, W.F. Young, I. Bancos, Pheochromocytoma characteristics and behavior differ depending on method of discovery. J. Clin. Endocrinol. Metab. 104(5), 1386-1393 (2019). https://doi.org/10.1210/jc.2018-01707

5. H. Yeomans, J. Calissendorff, C. Volpe, H. Falhammar, B. Mannheimer, Limited value of long-term biochemical follow-up in patients with adrenal incidentalomas-a retrospective cohort study. BMC Endocr. Disord. 15, 6 (2015). https://doi.org/10.1186/ s12902-015-0001-x

6. J. Patrova, I. Jarocka, H. Wahrenberg, H. Falhammar, Clinical outcomes in adrenal incidentaloma: experience from one center. Endocr. Pract.: Off. J. Am. Coll. Endocrinol. Am. Assoc. Clin. Endocrinol. 21(8), 870-877 (2015). https://doi.org/10.4158/ EP15618.OR

7. F. Mantero, M. Terzolo, G. Arnaldi, G. Osella, A.M. Masini, A. Ali, M. Giovagnetti, G. Opocher, A. Angeli, A survey on adrenal incidentaloma in Italy. Study Group on Adrenal Tumors of the Italian Society of Endocrinology. J. Clin. Endocrinol. Metab. 85 (2), 637-644 (2000). https://doi.org/10.1210/jcem.85.2.6372

8. H. Falhammar, M. Kjellman, J. Calissendorff, Treatment and outcomes in pheochromocytomas and paragangliomas: a study of 
110 cases from a single center. Endocrine 62(3), 566-575 (2018). https://doi.org/10.1007/s12020-018-1734-x

9. H. Falhammar, J. Calissendorff, C. Hoybye, Frequency of Cushing's syndrome due to ACTH-secreting adrenal medullary lesions: a retrospective study over 10 years from a single center. Endocrine 55(1), 296-302 (2017). https://doi.org/10.1007/s12020-016-1127-y

10. J.N. Gabi, M.M. Milhem, Y.E. Tovar, E.S. Karem, A.Y. Gabi, R. A. Khthir, Severe cushing syndrome due to an acth-producing pheochromocytoma: a case presentation and review of the literature. J. Endocr. Soc. 2(7), 621-630 (2018). https://doi.org/10. 1210/js.2018-00086

11. M. Fassnacht, W. Arlt, I. Bancos, H. Dralle, J. Newell-Price, A. Sahdev, A. Tabarin, M. Terzolo, S. Tsagarakis, O.M. Dekkers, Management of adrenal incidentalomas: European Society of Endocrinology Clinical Practice Guideline in collaboration with the European Network for the Study of Adrenal Tumors. Eur. J. Endocrinol. Eur. Fed. Endocr. Soc. 175(2), G1-G34 (2016). https://doi.org/10.1530/EJE-16-0467

12. J. Patrova, M. Kjellman, H. Wahrenberg, H. Falhammar, Increased mortality in patients with adrenal incidentalomas and autonomous cortisol secretion: a 13-year retrospective study from one center. Endocrine 58(2), 267-275 (2017). https://doi.org/10. 1007/s12020-017-1400-8

13. S. Y-Hassan, R. De Palma, Contemporary review on the pathogenesis of takotsubo syndrome: the heart shedding tears: Norepinephrine churn and foam at the cardiac sympathetic nerve terminals. Int J. Cardiol. 228, 528-536 (2017). https://doi.org/10. 1016/j.ijcard.2016.11.086

14. J.R. Ghadri, I.S. Wittstein, A. Prasad, S. Sharkey, K. Dote, Y.J. Akashi, V.L. Cammann, F. Crea, L. Galiuto, W. Desmet, T. Yoshida, R. Manfredini, I. Eitel, M. Kosuge, H.M. Nef, A. Deshmukh, A. Lerman, E. Bossone, R. Citro, T. Ueyama, D. Corrado, S. Kurisu, F. Ruschitzka, D. Winchester, A.R. Lyon, E. Omerovic, J.J. Bax, P. Meimoun, G. Tarantini, C. Rihal, Y.H. S, F. Migliore, J.D. Horowitz, H. Shimokawa, T.F. Luscher, C. Templin, International Expert Consensus Document on Takotsubo syndrome (Part I): clinical characteristics, diagnostic criteria, and pathophysiology. Eur. Heart J. 39(22), 2032-2046 (2018). https:// doi.org/10.1093/eurheartj/ehy076

15. S. Y-Hassan, K. Yamasaki, History of takotsubo syndrome: is the syndrome really described as a disease entity first in 1990? Some inaccuracies. Int J. Cardiol. 166(3), 736-737 (2013). https://doi. org/10.1016/j.ijcard.2012.09.183

16. K. Dote, H. Sato, H. Tateishi, T. Uchida, M. Ishihara, [Myocardial stunning due to simultaneous multivessel coronary spasms: a review of 5 cases]. J. Cardiol. 21(2), 203-214 (1991)

17. S. Y-Hassan, P. Tornvall, Epidemiology, pathogenesis, and management of takotsubo syndrome. Clin. Auton. Res 28(1), 53-65 (2018). https://doi.org/10.1007/s10286-017-0465-z

18. S. Y-Hassan, P. Tornvall, M. Tornerud, L. Henareh, Capecitabine caused cardiogenic shock through induction of global Takotsubo syndrome. Cardiovasc. Revasc. Med. 14(1), 57-61 (2013). https:// doi.org/10.1016/j.carrev.2012.10.001

19. I. Eitel, F. von Knobelsdorff-Brenkenhoff, P. Bernhardt, I. Carbone, K. Muellerleile, A. Aldrovandi, M. Francone, S. Desch, M. Gutberlet, O. Strohm, G. Schuler, J. Schulz-Menger, H. Thiele, M. G. Friedrich, Clinical characteristics and cardiovascular magnetic resonance findings in stress (takotsubo) cardiomyopathy. JAMA 306(3), 277-286 (2011). https://doi.org/10.1001/jama.2011.992

20. J.R. Ghadri, I.S. Wittstein, A. Prasad, S. Sharkey, K. Dote, Y.J. Akashi, V.L. Cammann, F. Crea, L. Galiuto, W. Desmet, T. Yoshida, R. Manfredini, I. Eitel, M. Kosuge, H.M. Nef, A. Deshmukh, A. Lerman, E. Bossone, R. Citro, T. Ueyama, D. Corrado, S. Kurisu, F. Ruschitzka, D. Winchester, A.R. Lyon, E. Omerovic, J.J. Bax, P. Meimoun, G. Tarantini, C. Rihal, Y.H. S, F. Migliore, J.D. Horowitz, H. Shimokawa, T.F. Luscher, C.
Templin, International Expert Consensus Document on Takotsubo syndrome (Part II): diagnostic workup, outcome, and management. Eur. Heart J. 39(22), 2047-2062 (2018). https://doi.org/10. 1093/eurheartj/ehy077

21. M.J. Cramer, B. De Boeck, P.G. Melman, G.J. Sieswerda, The 'broken heart' syndrome: what can be learned from the tears and distress? Neth. Heart J. 15(9), 283-285 (2007)

22. S.W. Sharkey, D.C. Windenburg, J.R. Lesser, M.S. Maron, R.G. Hauser, J.N. Lesser, T.S. Haas, J.S. Hodges, B.J. Maron, Natural history and expansive clinical profile of stress (tako-tsubo) cardiomyopathy. J. Am. Coll. Cardiol. 55(4), 333-341 (2010). https://doi.org/10.1016/j.jacc.2009.08.057

23. S. Y-Hassan, Clinical features and outcome of epinephrineinduced takotsubo syndrome: analysis of 33 published cases. Cardiovasc. Revasc. Med. 17(7), 450-455 (2016). https://doi.org/ 10.1016/j.carrev.2016.07.005

24. S. Y-Hassan, Serotonin norepinephrine re-uptake inhibitor (SNRI)-, selective norepinephrine reuptake inhibitor (S-NRI)-, and exogenously administered norepinephrine-induced takotsubo syndrome: analysis of published cases. Int. J. Cardiol. 231, 228-233 (2017). https://doi.org/10.1016/j.ijcard.2016.12.184

25. S. Y-Hassan, Clinical features and outcome of pheochromocytoma-induced takotsubo syndrome: analysis of 80 published cases. Am. J. Cardiol. 117(11), 1836-1844 (2016). https://doi.org/10.1016/j.amjcard.2016.03.019

26. N. Gagnon, S. Mansour, Y. Bitton, I. Bourdeau, Takotsubo-like cardiomyopathy in a large cohort of patients with pheochromocytoma and paraganglioma. Endocr. Pract. 23(10), 1178-1192 (2017). https://doi.org/10.4158/EP171930.OR

27. S. Y-Hassan, Plasma epinephrine levels and its causal link to takotsubo syndrome revisited: critical review with a diverse conclusion. Cardiovasc. Revasc. Med. (2018). https://doi.org/10. 1016/j.carrev.2018.10.026

28. S. Y-Hassan, Spontaneous coronary artery dissection and takotsubo syndrome: an often overlooked association; review. Cardiovasc. Revasc. Med. 19(6), 717-723 (2018). https://doi.org/10. 1016/j.carrev.2018.02.002

29. S. Y-Hassan, S. Holmin, G. Abdula, F. Bohm, Thrombo-embolic complications in takotsubo syndrome: review and demonstration of an illustrative case. Clin. Cardiol. (2018). https://doi.org/10. $1002 /$ clc. 23137

30. S. Y-Hassan, Acute cardiac sympathetic disruption in the pathogenesis of the takotsubo syndrome: a systematic review of the literature to date. Cardiovasc. Revasc. Med. 15(1), 35-42 (2014). https://doi.org/10.1016/j.carrev.2013.09.008

31. P.D. Van Vliet, H.B. Burchell, J.L. Titus, Focal myocarditis associated with pheochromocytoma. N. Engl. J. Med 274(20), 1102-1108 (1966). https://doi.org/10.1056/NEJM196605192742002

32. P. McGonigle, S.W. Webb, A.A. Adgey, Phaeochromocytoma: an unusual cause of chest pain. Br. Med. J. (Clin. ResEd) 286(6376), 1477-1478 (1983)

33. J.G. Wiswell, R.M. Crago, Reversible cardiomyopathy with pheochromocytoma. Trans. Am. Clin. Clim. Assoc. 80, 185-195 (1969)

34. T.R. Shaw, P. Rafferty, G.W. Tait, Transient shock and myocardial impairment caused by phaeochromocytoma crisis. Br. Heart J. 57(2), 194-198 (1987)

35. S. Khattak, I. Sim, L. Dancy, B. Whitelaw, D. Sado, Phaeochromocytoma found on cardiovascular magnetic resonance in a patient presenting with acute myocarditis: an unusual association. BMJ Case Rep. 2018 (2018). https://doi.org/10.1136/bcr-2017222621

36. A. Rolf, H.M. Nef, H. Mollmann, C. Troidl, S. Voss, G. Conradi, J. Rixe, H. Steiger, K. Beiring, C.W. Hamm, T. Dill, Immunohistological basis of the late gadolinium enhancement phenomenon in tako-tsubo cardiomyopathy. Eur. Heart J. 30(13), 1635-1642 (2009). https://doi.org/10.1093/eurheartj/ehp140 
37. P.E. Mattman, Successful removal of a pheochromocytoma four weeks after acute myocardial infarction. Am. J. Cardiol. 8, 426-430 (1961)

38. J.G. Nirgiotis, R.J. Andrassy, Pheochromocytoma and acute myocardial infarction. South Med. J. 83(12), 1478-1480 (1990)

39. M. Kashiura, S. Amagasa, H. Tamura, A. Shimoyama, T. Moriya, S.T. Tombstone, elevation in Takotsubo cardiomyopathy. Acute Med. Surg. 6(1), 87-88 (2019). https://doi.org/10.1002/ams2.377

40. C.R. Jessurun, K. Adam, K.J. Moise Jr., S. Wilansky, Pheochromocytoma-induced myocardial infarction in pregnancy. A case report and literature review. Tex. Heart Inst. J. 20(2), 120-122 (1993)

41. J. Sode, L.C. Getzen, D.P. Osborne, Cardiac arrhythmias and cardiomyopathy associated with pheochromocytomas. Report of three cases. Am. J. Surg. 114(6), 927-931 (1967)

42. Case records of the Massachusetts General Hospital., Weekly clinicopathological exercises. Case 15-1988. A 26-year-old woman with cardiomyopathy, multiple strokes, and an adrenal mass. N. Engl. J. Med 318(15), 970-981 (1988). https://doi.org/ 10.1056/NEJM198804143181507

43. M. Batisse-Lignier, B. Pereira, P. Motreff, R. Pierrard, C. Burnot, C. Vorilhon, S. Maqdasy, B. Roche, F. Desbiez, G. Clerfond, B. Citron, J.R. Lusson, I. Tauveron, R. Eschalier, Acute and chronic pheochromocytoma-induced cardiomyopathies: different prognoses?: a systematic analytical review. Med. (Baltim.) 94(50), e2198 (2015). https://doi.org/10.1097/MD.0000000000002198

44. I.S. Wittstein, Stress cardiomyopathy: a syndrome of catecholamine-mediated myocardial stunning? Cell Mol. Neurobiol. 32(5), 847-857 (2012). https://doi.org/10.1007/s10571-0129804-8

45. K. Iga, H. Gen, G. Tomonaga, T. Matsumura, K. Hori, Reversible left ventricular wall motion impairment caused by pheochromocytoma-a case report. Jpn Circ. J. 53(7), 813-818 (1989)

46. F. Roubille, G. Tournant, C. Sportouch-Dukhan, J.M. Davy, C. Piot, Recurrent severe acute apical-sparing left ventricular dysfunction in a young woman: don't forget pheochromocytoma. Ann. Cardiol. Angeiol. (Paris) 59(1), 52-53 (2010). https://doi. org/10.1016/j.ancard.2009.04.004

47. S.B. Karch, M.E. Billingham, Myocardial contraction bands revisited. Hum. Pathol. 17(1), 9-13 (1986)

48. H.M. Nef, H. Mollmann, S. Kostin, C. Troidl, S. Voss, M. Weber, T. Dill, A. Rolf, R. Brandt, C.W. Hamm, A. Elsasser, Tako-Tsubo cardiomyopathy: intraindividual structural analysis in the acute phase and after functional recovery. Eur. Heart J. 28(20), 2456-2464 (2007). https://doi.org/10.1093/eurheartj/ehl570

49. A. Frustaci, F. Loperfido, N. Gentiloni, M. Caldarulo, E. Morgante, M.A. Russo, Catecholamine-induced cardiomyopathy in multiple endocrine neoplasia. A histologic, ultrastructural, and biochemical study. Chest 99(2), 382-385 (1991)

50. C. Templin, J.R. Ghadri, J. Diekmann, L.C. Napp, D.R. Bataiosu, M. Jaguszewski, V.L. Cammann, A. Sarcon, V. Geyer, C.A. Neumann, B. Seifert, J. Hellermann, M. Schwyzer, K. Eisenhardt, J. Jenewein, J. Franke, H.A. Katus, C. Burgdorf, H. Schunkert, C. Moeller, H. Thiele, J. Bauersachs, C. Tschope, H.P. Schultheiss, C.A. Laney, L. Rajan, G. Michels, R. Pfister, C. Ukena, M. Bohm, R. Erbel, A. Cuneo, K.H. Kuck, C. Jacobshagen, G. Hasenfuss, M. Karakas, W. Koenig, W. Rottbauer, S.M. Said, R.C. BraunDullaeus, F. Cuculi, A. Banning, T.A. Fischer, T. Vasankari, K.E. Airaksinen, M. Fijalkowski, A. Rynkiewicz, M. Pawlak, G. Opolski, R. Dworakowski, P. MacCarthy, C. Kaiser, S. Osswald, L. Galiuto, F. Crea, W. Dichtl, W.M. Franz, K. Empen, S.B. Felix, C. Delmas, O. Lairez, P. Erne, J.J. Bax, I. Ford, F. Ruschitzka, A. Prasad, T.F. Luscher, Clinical features and outcomes of takotsubo (stress) cardiomyopathy. N. Engl. J. Med 373(10), 929-938 (2015). https://doi.org/10.1056/NEJMoa1406761
51. V. Agarwal, G. Kant, N. Hans, F.H. Messerli, Takotsubo-like cardiomyopathy in pheochromocytoma. Int J. Cardiol. 153(3), 241-248 (2011). https://doi.org/10.1016/j.ijcard.2011.03.027

52. A.R. Lyon, P.S. Rees, S. Prasad, P.A. Poole-Wilson, S.E. Harding, Stress (Takotsubo) cardiomyopathy-a novel pathophysiological hypothesis to explain catecholamine-induced acute myocardial stunning. Nat. Clin. Pract. Cardiovasc Med 5(1), 22-29 (2008). https://doi.org/10.1038/ncpcardio1066

53. B. Flam, M. Broome, B. Frenckner, R. Branstrom, M. Bell, Pheochromocytoma-Induced inverted takotsubo-like cardiomyopathy leading to cardiogenic shock successfully treated with extracorporeal membrane oxygenation. J. Intensive Care Med. 30 (6), 365-372 (2015). https://doi.org/10.1177/0885066614552992

54. A.G. Ferreira, T. Nunes da Silva, S. Alegria, M.C. Cordeiro, J. Portugal, Paraganglioma presenting as stress cardiomyopathy: case report and literature review. Endocrinol Diabetes Metab. Case Rep. 2019 (2019). https://doi.org/10.1530/EDM-19-0017

55. G. Di Palma, G.P. Daniele, F. Antonini-Canterin, R. Piazza, G.L. Nicolosi, Cardiogenic shock with basal transient left ventricular ballooning (Takotsubo-like cardiomyopathy) as first presentation of pheochromocytoma. J. Cardiovasc. Med. (Hagerstown) 11(7), 507-510 (2010). https://doi.org/10.2459/JCM.0b013e32832b4ccc

56. S. Kaese, C. Schulke, D. Fischer, P. Lebiedz, Pheochromocytomainduced takotsubo-like cardiomyopathy and global heart failure with need for extracorporal life support. Intensive Care Med. 39(8), 1473-1474 (2013). https://doi.org/10.1007/s00134-013-2942-8

57. A. Giavarini, A. Chedid, G. Bobrie, P.F. Plouin, A. Hagege, L. Amar, Acute catecholamine cardiomyopathy in patients with phaeochromocytoma or functional paraganglioma. Heart 99(19), 1438-1444 (2013). https://doi.org/10.1136/heartjnl-2013-304073

58. M. Gianni, F. Dentali, A.M. Grandi, G. Sumner, R. Hiralal, E. Lonn, Apical ballooning syndrome or takotsubo cardiomyopathy: a systematic review. Eur. Heart J. 27(13), 1523-1529 (2006). https://doi.org/10.1093/eurheartj/eh1032

59. E. Lassnig, T. Weber, J. Auer, R. Nomeyer, B. Eber, Pheochromocytoma crisis presenting with shock and tako-tsubo-like cardiomyopathy. Int J. Cardiol. 134(3), e138-e140 (2009). https:// doi.org/10.1016/j.ijcard.2008.03.012

60. H. Ueda, Y. Hosokawa, U. Tsujii, M. Miyawaki, N. Mitsusada, Y. Yasuga, H. Hiraoka, S. Nakatsuka, An autopsy case of left ventricular apical ballooning probably caused by pheochromocytoma with persistent ST-segment elevation. Int J. Cardiol. 149(2), e50-e52 (2011). https://doi.org/10.1016/j.ijcard.2009.03.096

61. S. Y-Hassan, Recurrent takotsubo syndrome triggered by undiagnosed pheochromocytoma. Int J. Cardiol. 187, 369-371 (2015). https://doi.org/10.1016/j.ijcard.2015.03.220

62. J.W. Lenders, Q.Y. Duh, G. Eisenhofer, A.P. Gimenez-Roqueplo, S.K. Grebe, M.H. Murad, M. Naruse, K. Pacak, W.F. Young Jr., S. Endocrine, Pheochromocytoma and paraganglioma: an endocrine society clinical practice guideline. J. Clin. Endocrinol. Metab. 99(6), 1915-1942 (2014). https://doi.org/10.1210/jc.20141498

63. K. Pacak, Preoperative management of the pheochromocytoma patient. J. Clin. Endocrinol. Metab. 92(11), 4069-4079 (2007). https://doi.org/10.1210/jc.2007-1720

64. J. Naranjo, S. Dodd, Y.N. Martin, Perioperative management of pheochromocytoma. J. Cardiothorac. Vasc. Anesth. 31(4), 1427-1439 (2017). https://doi.org/10.1053/j.jvca.2017.02.023

65. E.L. Bravo, R. Tagle, Pheochromocytoma: state-of-the-art and future prospects. Endocr. Rev. 24(4), 539-553 (2003). https://doi. org/10.1210/er.2002-0013

66. D. Di Vece, R. Citro, V.L. Cammann, K. Kato, S. Gili, K.A. Szawan, J. Micek, S. Jurisic, K.J. Ding, B. Bacchi, M. Schwyzer, A. Candreva, E. Bossone, F. D'Ascenzo, A. Sarcon, J. Franke, L. C. Napp, M. Jaguszewski, M. Noutsias, T. Munzel, M. Knorr, S. 
Wagner, H.A. Katus, C. Burgdorf, H. Schunkert, H. Thiele, J. Bauersachs, C. Tschope, B. Pieske, L. Rajan, G. Michels, R. Pfister, A. Cuneo, C. Jacobshagen, G. Hasenfubeta, M. Karakas, W. Koenig, W. Rottbauer, S.M. Said, R.C. Braun-Dullaeus, A. Banning, F. Cuculi, R. Kobza, T.A. Fischer, T. Vasankari, K.E.J. Airaksinen, G. Opolski, R. Dworakowski, P. MacCarthy, C. Kaiser, S. Osswald, L. Galiuto, F. Crea, W. Dichtl, K. Empen, S. B. Felix, C. Delmas, O. Lairez, I. El-Battrawy, I. Akin, M.
Borggrefe, E. Gilyarova, A. Shilova, M. Gilyarov, J. Horowitz, M. Kozel, P. Tousek, P. Widimsky, D.E. Winchester, C. Ukena, C. Di Mario, A. Prasad, M. Bohm, J.J. Bax, T. Luscher, F. Ruschitzka, J.R. Ghadri, C. Templin, Outcomes associated with cardiogenic shock in Takotsubo syndrome: results from the International Takotsubo Registry. Circulation 139(3), 413-415 (2019). https:// doi.org/10.1161/CIRCULATIONAHA.118.036164 